\title{
PEMANFAATAN BAHAN PANGAN MASYARAKAT DESA GOA BOMA KECAMATAN MONTERADO KABUPATEN BENGKAYANG
}

\author{
(Foodstaffs Utilization in the Community of Goa Boma Village Subdistrict Monterado \\ Bengkayang District)
}

\author{
Suriana Wiwik, S.M Kartikawati, M. Sofwan Anwari \\ Fakultas Kehutanan Universitas Tanjungpura Pontianak. J1. Daya Nasional Pontianak 78124 \\ E-mail : surianawiwik@gmail.com
}

\begin{abstract}
Food crops have long been used by the people of Goa Boma Village Monterado District Bengkayang Regency because of their simple processing and considerable availability in the forest. Based on the conditions of limitied infrastructure, accessibility and markets, it is interesting to conduct research on the Utilization of Foodstuffs at Goa Boma Village Monterado District Bengkayang Regency. The purpose of this study was to obtain data of the species and utilization pattern of plant utilization for foodstaff at Goa Boma Village. The research method is a survey method and data collection technique with interviews. Determination respondents by purposive sampling and addition also conducted abservations and literature study. Based on the results of interviews that have been conducted obtained as many as 94 spices of Goa Boma Village Monterado District Bengkayang Regency as food. Utilization patterns used as fruits were $(37,23 \%)$, vegetables $(27,23 \%)$, seasonings $(13,82 \%)$, drinks $(5,31 \%)$, carbohydrates $(4,25 \%)$ and cereals $(6,38 \%)$.
\end{abstract}

Keywords : Food Crops, Goa Boma Village, Utilization

\section{PENDAHULUAN}

Menurut kamus besar Bahasa Indonesia, tumbuhan pangan adalah segala sesuatu yang tumbuh hidup, berbatang, berakar, berdaun, dan dapat dimakan atau dikonsumsi oleh manusia. Bahan pangan yang dimaksud adalah makanan pokok, tumbuhan, minuman, bumbu masakan, dan rempah-rempah (Saepuddin dalam Fakhorzi, 2009). Pangan diartikan sebagai segala sesuatu yang bersumber dari hayati dan non hayati, baik yang diolah maupun tidak diolah. Pangan diperuntukkan bagi konsumsi manusia sebagai makanan atau minuman, termasuk bahan tambahan pangan, bahan baku pangan dan bahanbahan lain yang digunakan dalam proses penyiapan, pengolahan atau pembuatan makanan atau minuman.

Tumbuhan bahan pangan telah lama dimanfaatkan masyarakat Desa Goa Boma Kecamatan Monterado Kabupaten Bengkayang karena pengolahannya yang sederhana dan ketersediaannya cukup banyak di dalam hutan. Sejak dulu secara turun-temurun masyarakat desa terbiasa memanfaatkan sumber-sumber pangan untuk memenuhi kebutuhan pangan pokok sehari-hari. Tumbuhan pangan lokal juga masih banyak dimanfaatkan karena di Desa Goa Boma tidak ada pasar. Guna menuju pasar terdekat di Kota Singkawang memerlukan waktu jarak tempuh sekitar 1 jam dengan kondisi jalan yang banyak lubang dan pada saat musim hujan sulit 
dilalui. Berdasarkan kondisi keterbatasan sarana prasarana, aksebilitas dan pasar maka menarik untuk dilakukan penelitian mengenai Pemanfaatan Bahan Pangan Masyarakat Desa Goa Boma Kecamatan Monterado Kabupaten Bengkayang. Tujuan penelitian ini untuk mendapatkan data jenis-jenis dan pola pemanfaatan tumbuhan bahan pangan di Desa Goa Boma Kecamatan Monterado Kabupaten Bengkayang.

\section{METODE PENELITIAN}

Penelitian ini dilaksanakan di Desa Goa Boma Kecamatan Monterado Kabupaten Bengkayang dengan waktu penelitian lebih kurang 4 minggu di lapangan dari tanggal 8 Agustus sampai 8 September 2018. Metode penelitian yang digunakan dalam penelitian ini adalah metode survei, teknik pengumpulan data dengan wawancara. Penentuan responden dilakukan secara purposive sampling selain itu dilakukan juga observasi dan studi literatur. Menurut Sugiyono (2014) purposive sampling adalah teknik pengambilan sampel sumber data yang didasarkan dengan pertimbangan tertentu. Pertimbangan tertentu yang dimaksudkan adalah responden atau orang yang dianggap paling tahu tentang apa yang diharapkan atau mungkin orang yang menguasai sehingga akan memudahkan peneliti menjelajahi objek/situasi sosial yang diteliti. Kriteria informan yang digunakan dalam penelitian ini yaitu informan merupakan warga asli Desa Goa Boma yang memiliki pengetahuan luas mengenai nama lokal tumbuhan bahan pangan dan dapat memberikan informasi yang dicari tentang pemanfaatan tumbuhan bahan pangan seperti petani yang masih memiliki ladang dan ibu rumah tangga yang usianya di atas 50 tahun serta informan merupakan masyarakat yang tinggal di Desa Goa Boma lebih dari 5 tahun dan dalam kesehariannya menggunakan tumbuhan bahan pangan.

\section{HASIL DAN PEMBAHASAN Pemanfaatan Tumbuhan Sebagai Bahan Pangan}

Berdasarkan hasil wawancara yang telah dilakukan diperoleh sebanyak 94 jenis tumbuhan bahan pangan yang biasa dimanfaatkan oleh masyarakat Desa Goa Boma Kecamatan Monterado Kabupaten Bengkayang sebagai bahan pangan. Jumlah jenis tumbuhan berdasarkan kelompok bahan pangan secara lengkap dapat dilihat pada Tabel 1.

Tabel 1. Jumlah Kelompok Bahan Pangan (The number of food group)

\begin{tabular}{clc}
\hline No & \multicolumn{1}{c}{ Jenis bahan pangan } & Jumlah jenis \\
\hline 1 & Buah-buahan & 35 \\
2 & Sayur-sayuran & 35 \\
3 & Bumbu & 13 \\
4 & Minuman & 5 \\
5 & Karbohidrat & 4 \\
6 & Sereal & 5 \\
\hline
\end{tabular}

\section{Pemanfaatan Tumbuhan Sebagai Buah}

Buah-buahan merupakan kelompok komoditas yang besar dan 
beranekaragam. Definisi buah-buahan menurut Verhejj dan Coronel (1991) adalah jenis buah-buahan tahunan yang dapat dimakan baik dalam keadaan segar maupun yang telah dikeringkan yang umumnya dikonsumsi mentah. Buahbuahan terutama mengandung vitamin dan mineral untuk menyeimbangkan menu makanan. Jenis-jenis buah-buahan yang masih dicari di hutan diantaranya buah asam maram (Eleiodoxa conferta), mentawak (Artocarpus anisophyllus), rambai (Baccaurea motleyana), dan jambu monyet (Anacardium occidentale). Pemanfaatan tumbuhan sebagai buah disajikan pada Tabel 2.

Tabel 2. Jenis Pemanfaatan Tumbuhan Sebagai Buah (The type of plants utilization as fruit)

\begin{tabular}{|c|c|c|c|c|}
\hline No & Nama Lokal & Nama Umum & Nama Ilmiah & Lokasi \\
\hline 1 & Asapm & Manga & Mangifera indica & Perkarangan \\
\hline 2 & Kaumi & Asam maram & Eleiodoxa conferta & Hutan \\
\hline 3 & Barinang & Belimbing wuluh & Averrhoa bilimbi & Perkarangan \\
\hline 4 & Barinang merah & Belimbing merah & Baccaurea angulata & Hutan \\
\hline 5 & Belimbing & Belimbing & Averrhoa carambola & Perkarangan \\
\hline 6 & Koko & Kakao & Theobroma cacao & Perkarangan \\
\hline 7 & Duriatn & Durian & Durio zibethinus & Hutan \\
\hline 8 & Nyiur & Kelapa & Cocos nucifera & Perkarangan \\
\hline 9 & Nangkak hutan & Cempedak & Artocarpus integer & Hutan \\
\hline 10 & Nangkak & Nangka & Artocarpus heterophyllus & Hutan \\
\hline 11 & Jambu aik & Jambu air & Syzygium malaccense & Perkarangan \\
\hline 12 & Jambu batu & Jambu batu & Psidium guajava & Perkarangan \\
\hline 13 & Jambu monyet & Jambu monyet & Anacardium occidentale & Hutan \\
\hline 14 & Kadondong & Kedondong & Spondias dulcis & Perkarangan \\
\hline 15 & Rambutan & Rambutan & Nephelium lappaceum & Perkarangan \\
\hline 16 & Sarikatn & Langsat & Aglaia acida & Hutan \\
\hline 17 & Insupm & Salak hutan & Zalacca affinis & Hutan \\
\hline 18 & Manggis & Manggis & Garcinia mangostana & Perkaragan \\
\hline 19 & Mentawak & Mentawak & Artocarpus anisophyllus & Hutan \\
\hline 20 & Nanas & Nanas & Ananas comosus & Ladang \\
\hline 21 & Palomet & Sirsak & Annona muricata & Perkarangan \\
\hline 22 & Angkuukng lilin & Pisang mas & Musa acuminata & Perkarangan \\
\hline 23 & Angkuukng kapok & Pisang kapok & Musa brachycarpa & Perkarangan \\
\hline 24 & Angkuukng hutan & Pisang hutan & Musa acuminata & Hutan \\
\hline 25 & Ulap & Rambai & Baccaurea motleyana & Hutan \\
\hline 26 & Sukun & Sukun & Artocarpus altilis & Hutan \\
\hline 27 & Cermai & Cermai & Phyllanthus acidus & Perkarangan \\
\hline 28 & Kuranyi & Asam keranji & Dialium indum & Hutan \\
\hline 29 & Kopi & Kopi & Coffea sp & Hutan \\
\hline 30 & Somban & Rambusa & Passiflora foetida & Hutan \\
\hline 31 & Buah nasi & Kelat nenasi & Eugenia spicata & Hutan \\
\hline 32 & Asapm kaimantan & Bacang & Mangifera foetida & Hutan \\
\hline 33 & Salak & Salak & Salacca zalacca & Hutan \\
\hline 34 & Jambu kaleng & Jambu bol & Syzygium malaccense & Hutan \\
\hline 35 & Bunan & Pepaya & Carica papaya & Perkarangan \\
\hline
\end{tabular}

Sumber. Hasil Analisis Data Primer, 2018 
Berdasarkan hasil wawancara yang telah dilakukan diperoleh sebanyak 35 jenis tumbuhan bahan pangan sebagai buah yang biasa dimanfaatkan oleh masyarakat Dayak Kanayatn Di Desa Goa Boma Kecamatan Monterado Kabupaten Bengkayang. Buah tersebut diantaranya kelat nenasi (Eugenia spicata), Bacang (Mangifera foetida), Salak (Salacca zalacca), Jambu bol (Syzygium malaccense) dan Pepaya (Carica papaya).

\section{Pemanfaatan Tumbuhan Sebagai}

Sayur

Sayuran merupakan komoditas tumbuhan yang biasanya mengandung air atau yang dikonsumsi sebagai bahan makanan yang mengandung zat tepung dan kadang-kadang digunakan sedikit pada makanan untuk menambah rasa kelezatan makanan (Siemonsma dan Piluek, 1994). Jenis sayuran yang biasa dikonsumsi untuk masakan diantaranya adalah selada (Lactuca sativa Linn), katuk (Sauropus androgynus Merr), jenis-jenis kobis, kol (Brassica oleraceae), kangkung (Ipomoae aquatica Forst) dan sebagainya. Pemanfaatan tumbuhan sebagai sayuran disajikan pada Tabel 3. 
Tabel 3. Jenis Pemanfaatan Tubuhan Sebagai Sayur (The type of plants utilization as vegetables)

\begin{tabular}{|c|c|c|c|c|c|}
\hline No & Nama Lokal & Nama Umum & Nama Ilmiah & Bagian yg digunakan & Lokasi \\
\hline 1 & Bawang uma & Bawang kucai & Allium tuberosum & Seluruh bagian & Ladang \\
\hline 2 & Ano & Enau & Arenga pinnata & Umbut & Hutan \\
\hline 3 & Genjer & Genjer & Limnocharis flava & Seluruh bagian & Ladang \\
\hline 4 & Jarikng & Jengkol & $\begin{array}{l}\text { Pithecolobium } \\
\text { lobatum }\end{array}$ & Buah & Hutan \\
\hline 5 & Kacang panjang & Kacang panjang & Vigna unguiculata & Seluruh bagian & Ladang \\
\hline 6 & Kangkokng & Kangkug & Ipomea aquatica & Seluruh bagian & Perkarangan \\
\hline 7 & Kuat merah & Jamur rusa & Cervinus pluteus & Seluruh bagian & Hutan \\
\hline 8 & Kuat gabedor & Jamur kuping & Auricularia & Seluruh bagian & Hutan \\
\hline 9 & Kuat putih & Jamur putih & Pleurotus ostreatus & Seluruh bagian & Hutan \\
\hline 10 & Kuat sawit & Jamur sawit & Volvariella volvacea & Seluruh bagian & Hutan \\
\hline 11 & Baimikng & Labu kuning & Cucurbita moschata & Seluruh bagian & Ladang \\
\hline 12 & Laban & Leban & Vitex pubescens & Daun & Hutan \\
\hline 13 & Melinjo & Melinjo & Gnetum gnemon & Daun & Perkarangan \\
\hline 14 & Amidikng & Pakis merah & $\begin{array}{l}\text { Stenochlaena } \\
\text { palustris }\end{array}$ & Seluruh bagian & Hutan \\
\hline 15 & Pakuk ubatn & Pakis hijau & Pletycenum sp & Seluruh bagian & Hutan \\
\hline 16 & Pare & Pare & Momordica charantia & Buah & Ladang \\
\hline 17 & Pate & Petai & Parkia speciosa & Buah & Hutan \\
\hline 18 & Sawi & Sawi & Brassica juncea & Daun & Ladang \\
\hline 19 & Tarukng asam & Terong asam & Solanum ferox & Buah & Ladang \\
\hline 20 & Tarukng gentekng & Terong pipit & Solanum torvum & Buah & Perkarangan \\
\hline 21 & Antimun & Mentimun & Cucumis sativus & Buah dan daun & Ladang \\
\hline 22 & Tomat & Tomat & Solanum lycopersicum & Buah & Ladang \\
\hline 24 & Tangok tikala & Kecombrang & Etlingera elatior & Umbut & Hutan \\
\hline 25 & Daukng buatn & Daun simpur & Dillenia suffruticosa & Daun & Hutan \\
\hline 26 & Gamang & Kundur & Benincasa hispida & Buah dan daun & Ladang \\
\hline 27 & Kaade & Keladi & Colocasia esculenta & Buah & Ladang \\
\hline 28 & Rabukng & Rebung & Bambusa sp & Tunas & Hutan \\
\hline 29 & Cangkok manis & Cangkok manis & Sauropus androgynus & Daun & Perkarangan \\
\hline 30 & Mengkudu & Mengkudu & Morinda citrifolia & Daun & Hutan \\
\hline 31 & Kecipir & Kecipir & $\begin{array}{l}\text { Psophocarpus } \\
\text { tetragonolobus }\end{array}$ & Buah & Ladang \\
\hline 32 & Bayam & Bayam & Amaranthus spinosus & Daun & Ladang \\
\hline 33 & Angkuukng lilin & Pisang mas & Musa acuminata & Jantung & Perkarangan \\
\hline 34 & Angkuukng kapok & Pisang kapok & Musa brachycarpa & Jantung & Perkarangan \\
\hline 35 & Angkuukng hutan & Pisang hutan & Musa acuminata & Jantung & Hutan \\
\hline
\end{tabular}

Sumber. Hasil Analisis Data Primer, 2018

Berdasarkan hasil wawancara yang telah dilakukan diperoleh sebanyak 35 jenis tumbuhan bahan pangan sebagai sayur yang biasa dimanfaatkan oleh masyarakat Dayak Kanayatn Di Desa Goa Boma Kecamatan Monterado Kabupaten Bengkayang. Sayuran tersebut diantaranya Pakis merah (Stenochlaena palustris), Terong asam
(Solanum ferox) dan Rebung (Bambusa $s p)$.

\section{Pemanfaatan Tumbuhan Sebagai Bumbu}

Bumbu merupakan penyedap rasa atau aromatik asal sayuran yang diperoleh dari tumbuhan biasanya digunakan sebagai penyedap pada makanan atau masakan (Weiss, 2002). 
Tumbuhan yang digunakan sebagai penyedap rasa pada masakan diantaranya adalah, bawang merah (Allium cepa Linn), bawang putih (Allium sativum Linn), daun bawang
(Allium ampeloprasum Linn) dan seledri (Avium graveolens). Jenis tumbuhan yang dimanfaatkan sebagai bumbu disajikan pada Tabel 4

Tabel 4. Jenis Pemanfaatan Tumbuhan Sebagai Bumbu (The type of plants utilization as herbs)

\begin{tabular}{|c|c|c|c|c|c|}
\hline No & Nama Lokal & Nama Umum & Nama Ilmiah & Lokasi & Rasa/Efek \\
\hline 1 & $\begin{array}{l}\text { Daukng } \\
\text { ubah ube }\end{array}$ & Daun salam & $\begin{array}{l}\text { Syzygium } \\
\text { polyanthum }\end{array}$ & Hutan & $\begin{array}{l}\text { Menambah aroma } \\
\text { dan rasa pedas }\end{array}$ \\
\hline 2 & Ahiak & Jahe & Zingiber offcinale & Perkaranagn & Pedas \\
\hline 3 & Imo songkit & Jeruk nipis & Citrus aurantiifolia & Perkarangan & $\begin{array}{l}\text { Rasa asam dan } \\
\text { mengilangkan bau } \\
\text { amis }\end{array}$ \\
\hline 4 & Angkong & Lengkuas & Alpinia galanga & Perkarangan & $\begin{array}{l}\text { Menambah } \\
\text { aroma, rasa gurih } \\
\text { dan manis }\end{array}$ \\
\hline 5 & Cabe & Cabe rawit & Capsicum anпuит & Perkarangan & Pedas \\
\hline 6 & Sare & Serai & $\begin{array}{l}\text { Cymbopogon } \\
\text { ciratus }\end{array}$ & Perkarangan & Menambah aroma \\
\hline 7 & Unyit & Kunyit & Curcuma domestica & Perkarangan & $\begin{array}{l}\text { Menambah aroma } \\
\text { dan warna }\end{array}$ \\
\hline 8 & $\begin{array}{l}\text { Daukng } \\
\text { sansakng }\end{array}$ & Daun sengkuba & $\begin{array}{l}\text { Pycnarrhena } \\
\text { cauliflora }\end{array}$ & Hutan & $\begin{array}{l}\text { Menambah rasa } \\
\text { manis }\end{array}$ \\
\hline 9 & Cabe aik & Daun kesum & Polygonum minus & Perkarangan & $\begin{array}{l}\text { Menambah aroma } \\
\text { dan rasa pedas }\end{array}$ \\
\hline 10 & Bunga ikatn & Daun kemangi & $\begin{array}{l}\text { Ocimum } \\
\text { xcitriodorum }\end{array}$ & Perkarangan & $\begin{array}{l}\text { Menambah aroma } \\
\text { dan pedas }\end{array}$ \\
\hline 11 & $\begin{array}{l}\text { Asapm } \\
\text { kandis }\end{array}$ & Asam kandis & Garcinia bancana & Hutan & $\begin{array}{l}\text { Rasa asam dan } \\
\text { mengjilangkan } \\
\text { bau amis }\end{array}$ \\
\hline 12 & Sahakng & Lada & Piper nigrum & Kebun & Rasa pedas \\
\hline 13 & Guminting & Kemiri & $\begin{array}{l}\text { Aleurites } \\
\text { moluccanus }\end{array}$ & Hutan & $\begin{array}{l}\text { Menambah } \\
\text { minyak/ kental }\end{array}$ \\
\hline
\end{tabular}

Sumber. Hasil Analisis Data Primer, 2018

Berdasarkan hasil wawancara yang telah dilakukan diperoleh sebanyak 13 jenis tumbuhan bahan pangan sebagai bumbu yang biasa dimanfaatkan oleh masyarakat Dayak Kanayatn Di Desa Goa Boma Kecamatan Monterado Kabupaten Bengkayang. Tumbuhan tersebut biasanya berada di perkarangan karena sering digunakan sehari-hari seperti daun kesum (Polygonum minus) dan daun kemangi (Ocimum xcitriodorum). Tumbuhan yang berada di hutan dan dimanfaatakan sebagai bumbu biasanya diambil dalam jumlah yang banyak seperti daun salam (Syzygium polyanthum) dan asam kandis (Garcinia bancana).

\section{Pemanfaatan Tumbuhan Sebagai Minuman}

Minuman merupakan bahan yang sangat dibutuhkan oleh makhluk hidup, yang berguna bagi kelangsungan hidup. Definisi minuman adalah segala sesuatu yang dapat dikonsumsi dan dapat 
menghilangkan rasa haus (Cahyadi, 2005). Minuman umumnya berbentuk cair, jenis tumbuhan yang menghasilkan cairan yang biasa dimanfaatkan oleh masyarakat untuk bahan minum diantaranya, tebu (Saccharusm officinarum L), kelapa (Cocos nucifera), hanau (Arenga pinnata), dan lidah buaya (Aloe barbadensis Milleer). Pemanfaatan tumbuhan sebagai minuman disajikan pada Tabel 5.

Tabel 5. Jenis Pemanfaatan Tumbuhan Sebagai Minuman (The type of plants utilization as drinks)

\begin{tabular}{lllll}
\hline No & Nama Lokal & Nama Umum & Nama Ilmiah & Lokasi \\
\hline 1 & Selasih & Selasih & Ocimum basilicum & Perkarangan \\
2 & Lidah buaya & Lidah buaya & Aloe vera & Perkarangan \\
3 & Tabu & Tebu & Saccharusm officinarum & Ladang \\
4 & Pandan & Pandan & Pandanus amaryllifolius & Perkarangan \\
5 & Rosela & Rosela & Hibicus radiates & Hutan \\
\hline
\end{tabular}

Sumber. Hasil Analisis Data Primer, 2018

Berdasarkan hasil wawancara yang telah dilakukan diperoleh sebanyak 5 jenis tumbuhan bahan pangan sebagai minuman yang biasa dimanfaatkan oleh masyarakat di Desa Goa Boma Kecamatan Monterado Kabupaten Bengkayang. Tumbuhan tersebut diantaranya Lidah buaya (Aloe vera) yaitu tanaman yang sudah dibudidayakan dan ditanam di perkarangan, cara pemanfaatannya yaitu ambil cuci daging lidah buaya sampai tidak berlendir setelah itu direbus dan tambahkan gula pasir sampai gula larut, Tebu (Saccharusm officinarum) cara pemanfaatannya yaitu giling tebu menggunakan mesin penggiling dan ambil airnya dan tambahkan es batu. Jenis tumbuhan yang jarang dimanfaatkan oleh masyarakat yaitu
Rosela (Hibicus radiates) karena mulai sulit didapatkan.

\section{Pemanfaatan Tumbuhan Sebagai Karbohidrat}

Definisi tumbuhan sebagai sumber karbohidrat adalah jenis tumbuhan yang mengandung zat tepung atau zat gula sebagai cadangan makanan. Karbohidrat merupakan sumber utama energi dalam makanan untuk manusia. Beberapa jenis tumbuhan yang merupakan karbohidrat diantaranya adalah sagu (Metroxylon sagu Rottbell), Padi (Oryza sativa Linn), singkong (Manihot utillisma Pohl), ubi jalar (Ipomoea batatas Lamk), dan lain sebagainya (Flach dan Rumawas, 1996). Pemanfaatan tumbuhan untuk karbohidrat disajikan pada Tabel 6.

Tabel 6. Jenis Pemanfaatan Tumbuhan Sebagai Karbohidrat (The type of plants utilization as carbohydrates)

\begin{tabular}{llllll}
\hline No & $\begin{array}{l}\text { Nama } \\
\text { Lokal }\end{array}$ & $\begin{array}{l}\text { Nama } \\
\text { Umum }\end{array}$ & Nama Ilmiah & Lokasi & Bagian yang digunakan \\
\hline 1 & Manggala & Ubi kayu & Manihot utilissima & Ladang & Umbi \\
2 & Tea & Ubi jalar & Ipomea batatas & Ladang & Umbi \\
3 & Muukng & Sagu & Metroxylon $s p$ & Hutan & Umbut \\
\hline
\end{tabular}

Sumber. Hasil Analisis Data Primer, 2018 
Berdasarkan hasil wawancara yang telah dilakukan diperoleh sebanyak 3 jenis tumbuhan bahan pangan sebagai karbohidrat yang biasa dimanfaatkan oleh masyarakat di Desa Goa Boma Kecamatan Monterado Kabupaten Bengkayang. Tumbuhan tersebut diantaranya Ubi kayu (Manihot utilissima), Ubi jalar (Ipomea batatas) dan Sagu (Metroxylon $s p$ ) biasa tumbuh di sekitar rawa dan lahan berlumpur, cara pemanfaatannya yaitu ambil bagian dan kupas batang sagu yang lunak lalu ditumbuk setelah itu masukan kedalam air lalu pisahkan ampar dari air stelah itu biarkan selama \pm 1 hari.

\section{Pemanfaatan Tumbuhan Sebagai Sereal}

Tabel 7. Jenis Pemanfaatan Tumbuhan Sebagai Sereal (The type of plants utilization as cereals)

\begin{tabular}{lllll}
\hline No & Nama Lokal & Nama Umum & Nama Ilmiah & Lokasi \\
\hline 1 & Padi mototn & Padi putih & Oryza sativa & Ladang \\
2 & Padi poek & Padi ketan & Oryza sativa & Sawah \\
3 & Padi jampehak & Padi merah & Oryza sativa & Ladang \\
4 & Jagokng & Jagung & Zea mays & Kebun \\
5 & Kacang bulu & Kedelai & Glycine max & Ladang \\
6 & Kacang tanah & Kacang tanah & Arachis hypogeae & Ladang \\
\hline \multicolumn{5}{l}{ Sumber. Hasil Analisis Data Primer, 2018}
\end{tabular}

Berdasarkan hasil wawancara yang telah dilakukan diperoleh sebanyak 6 jenis tumbuhan bahan pangan sebagai sereal yang biasa dimanfaatkan oleh masyarakat. Tumbuhan tersebut diantaranya padi mototn/padi ladang dan padi jampehak/padi merah biasanya ditanam di daerah dataran tinggi dan lahan kering yang jauh dari pemukiman dengan jarak tempuh sekitar \pm 1 jam, sedangkan padi poek ditanam di dataran rendah di lahan yang digarap dan diairi untuk menanam padi dengan jarak tempuh \pm 1 jam dari
Jenis tumbuhan penghasil sereal menurut Grubben dan Partohardjono (1996) dibatasi pada famili Gramineae, sebab jenis yang paling banyak dimanfaatkan dan digunakan adalah famili ini. Miasalnya, padi (Oryza sativa Linn), jagung (Zea mays Linn), sorgum (Sorghum biocolor (L) Moench), jawawut (Panicum miliaceum L), gandum (Triticum spp) dan lain sebagainya. Sereal merupakan jenis bahan makanan yang penting bagi manusia sebagai sumber nutrisi dan kekuatan bagi manusia. Pemanfaatan tumbuhan untuk sereal disajikan pada Tabel 7. pemukiman. Perbedaannya terletak pada lahan yang dipergunakan untuk menanam dimana padi ladang ditanam secara tidak menetap pada lahan bekas hutan sedangka padi sawah ditanam pada lahan permanen. Sudah banyak warga yang memilih menanam jagung karena padi panen 1 kali setahun sedangkan jagung 3-4 kali dalam setahun dan nilainya lebih mahal.

\section{Kesimpulan}

Berdasarkan hasil penelitian dan pembahasan dapat disimpulkan sebagai berikut : 
1. Jenis tumbuhan bahan pangan yang dimanfaatkan oleh masyarakat Desa Goa Boma Kecamatan Monterado Kabupaten Bengkayang yaitu sebanyak 94 jenis dan 45 famili.

2. Pola pemanfaatan digunakan sebagai buah-buahan, sayur-sayuran, bumbu, minuman, karbohidrat, dan sereal. Bagian yang digunakan sebagai buah, daun, seluruh bagian, umbut, jantung, biji dan batang yaitu diperoleh 97 jenis karena ada tumbuhan yang memiliki 2 jenis pola pemanfaatan.

\section{Saran}

Perlu dilakukan kegiatan pembudidayaan tumbuhan bahan pangan, agar tumbuhan bahan pangan tersebut tidak punah, mengingat ada beberapa dari tumbuhan bahan pangan khususnya yang ada dihutan dan paling sering digunakan masyarakat Desa Goa Boma Kecamatan Monterado Kabupaten Bengkayang.

\section{DAFTAR PUSTAKA}

Cahyadi, W. 2005. Analisis dan Aspek Kesehatan Bahan Tambahan Pangan. Penerbit Bumi Aksara. Jakarta.

Flach M dan F Rumawas. 1996. Plant Resources of South-East Asia. London : Backhuys Publisher.

Grubben GJH dan S Partohardjono. 1996. Plant Resources of South-East Asia no

Cereals.Prosea.Bogor.

Tengah. Tesis Pada Sekolah Pascasarjana IPB. Bogor.

Martin, GJ. 1998. Etnobotani: Sebuah Manual Pemeliharaan Manusia dan Tumbuhan

[diterjemahan oleh Maryati Mohamed]. Edisi bahasa melayu. Malaysia: Natural History Publications (Borneo) Sdn. Bhd.

Siemonsma, JS. dan K Piluek. 1994. Capsicum L. In: J.M. Poulos (Ed). Prosea, Plant Resources of SouthEast Asia 8, Vegetable. Prosea Foundation. Bogor. P 136-140.

Sugiyono. 2014. Metode Penelitian Manajemen. Bandung. Alfabeta.

Suryadharma. 2008. Etnobotani. Diktat Kuliah Jurusan Pendidikan Biologi MIPA: Universitas Negeri Yogyakarta.

Tatang L, F Victor, S Uwan, MM Sood, A Bayer, D Hasiwan dan Silun. 2000. Kalimantan: Bumi Yang Kaya Makanan. Pontianak: Masyarakat Adat Dayak Mempawah dan Dayak Jalai Bekerjasama Dengan Institut Dayakologi.

Verhejj, EWM dan R.E Coronel. 1997. Sumberdaya Nabati Asia Tenggara 2. Penerjemah S. Danimihardja; H. Sutarno; N.W Utami dan D.S.H Hopsen. Gramedia Pustaka Utama. Jakarta.

Weiss, EA. 2002. Spice Crops. Wallingford, England; New York: CABI Publishing.

Kartikawati, SM. 2004. Pemanfaatan Sumberdaya Tumbuhan Oleh Masyarakat Dayak Meratus di Kawasan Hutan Pegunungan Meratus Kabupaten Hulu Sungai 